\title{
Perioperative FLOT chemotherapy plus surgery for oligometastatic esophagogastric adenocarcinoma: surgical outcome and overall survival
}

\author{
Mira Runkel ${ }^{1 *} \mathbb{0}$, Rasmus Verst ${ }^{1}$, Julia Spiegelberg ${ }^{1}$, Stefan Fichtner-Feigl ${ }^{1}$, Jens Hoeppner ${ }^{1,2}$ and Torben Glatz ${ }^{1,3}$
}

\begin{abstract}
Background: Guidelines do not recommend surgery for patients with oligometastatic disease from esophagogastric adenocarcinoma (EGAC), although some studies suggest a more favorable survival. We analyzed the outcome of oligometastatic EGAC receiving FLOT chemotherapy followed by surgery.

Methods: The data of patients with either pre-therapeutic, post-neoadjuvant or intraoperative clinical diagnosis of oligometastatic EGAC were extracted from a prospective database of the 2009-2018 treatment period. 48 consecutive patients were identified with oligometastatic disease, who underwent perioperative chemotherapy plus surgery. We retrospectively analyzed surgical outcome and overall survival.

Results: The overall 5-year survival was 18\%. 12 patients (25\%) with pre-therapeutic oligometastatic EGAC, who had no histologic vital tumor evidence of metastases after surgery had a survival rate of $48 \%$ compared to an $11 \% 5$-year survival rate of 36 patients (75\%), who had histologic vital tumor metastatic evidence after FLOT chemotherapy and surgical resection $(p=0.012)$. The survival rates after RO, R1 and R2 (non-resected metastases) resection were $21 \%$ $(n=33), 0 \%(n=4)$ and $17 \%(n=11)$, respectively $(p=0.273)$.

Conclusion: Oligometastatic EGAC is associated with poor overall survival even after complete resection of all tumor manifestations. The subgroup of patients with a complete histologic response of metastatic lesions to neoadjuvant FLOT shows 5-year survival rates similar to non-metastatic EGAC.

Trial registration Not applicable.
\end{abstract}

Keywords: Esophageal cancer, Gastric cancer, Adenocarcinoma, Perioperative chemotherapy, Oligometastases

\section{Background}

Different randomized controlled trials (RCT) have demonstrated superior results of perioperative chemotherapy plus surgery for non-metastatic esophagogastric cancers (EGAC) compared to surgery alone [1-4]. The chemotherapy of choice in Europe is the FLOT

\footnotetext{
*Correspondence: mira.runkel@uniklinik-freiburg.de

${ }^{1}$ Department of General - and Visceral Surgery, Medical Center, University

of Freiburg, Hugstetterstrasse 55, 79106 Freiburg, Germany

Full list of author information is available at the end of the article
}

regime, consisting of Docetaxel $50 \mathrm{mg} / \mathrm{m}^{2}$, Oxaliplatin $85 \mathrm{mg} / \mathrm{m}^{2}$, Leucovorin $200 \mathrm{mg} / \mathrm{m}^{2}$ and 5FU $2600 \mathrm{mg} /$ $\mathrm{m}^{2}$. FLOT is associated with overall better survival compared to ECF/ECX regimes [5]. One RCT showed survival rates of 50 months for perioperative FLOT therapy vs 35 months for patients receiving ECF/ECX regimes [5]. Perioperative chemotherapy has been adopted by national and international guidelines for locally advanced but not for metastatic EGAC $[3,6]$ for which palliative chemotherapy is recommended. There 
is, however, great uncertainty about the best management for patients with oligometastatic EGAC. Oligometastastic disease is defined as less than five distant, potentially resectable metastases, eg liver metastases and limited peritoneal carcinomatosis. It is used to described a state between limited and disseminated metastatic disease, with the potential intention of curative treatment [7]. The evidence is low with some retrospective studies suggesting prolonged survival after surgical resection of metastases from EGAC tumors [8-10]. The ongoing RENAISSANCE trial, a multicenter RCT, comparing the effect of chemotherapy alone vs chemotherapy followed by surgery for patients with oligometastatic EGAC is anticipated to shed light on the best treatment modality [10]. As we await the results, we conducted an analysis of our prospective database, evaluating the outcome and 5-year survival of patients with oligometastatic EGAC, who received perioperative FLOT chemotherapy plus surgery of the primary tumor and its metastases.

\section{Methods}

Between June 2009 and April 2018277 patients had locally advanced EGAC, who were treated with FLOT chemotherapy and subsequent surgery at the Medical Center of the University of Freiburg. Out of these 277 patients, 48 patients with oligometastatic disease, including potentially resectable peritoneal carcinomatosis, underwent perioperative FLOT chemotherapy followed by surgery. The majority of patients with metastatic disease received palliative chemotherapy alone, and were not treated by our department. These patients were not included in our analysis. The metastases were found either at the time of initial diagnosis (cM1), during post-neoadjuvant staging investigations (ycM1), or found intraoperatively. As 9 patients were lost to follow up, a total of 220 patients showed no metastases at time of diagnosis (cM0). Data had been prospectively collected and retrospectively analyzed in this study. Patient demographics, pre- and postoperative tumor stages, histopathological regression (HPR), perioperative complications and administration of perioperative chemotherapy were correlated with overall survival of the patients.

Complications were classified according to Clavien Dindo [11] and tumor regression according to Becker et al. [12]. Survival data was obtained from the cancer registry of the Cancer Centre of our Medical Center. Inclusion in the cancer registry required informed consent, which was obtained from all patients. The study was approved by the Medical Ethics Committee of the University of Freiburg (File number 253/19).

\section{Diagnostic work up and Staging}

All patients with symptoms suggesting the presence of esophageal or gastric cancers were taken through diagnostic and staging work up according to German S3 guidelines [6]. This includes a thorough medical history and physical exam, as well as upper GI endoscopy with several biopsies, endoscopic ultrasound if technically possible and a CT Thorax/Abdomen to exclude distant metastases. Diagnostic laparoscopy with peritoneal biopsies and PET-CT scans were added in selected cases of suspected peritoneal carcinomatosis or distant metastases, otherwise distant metastases were diagnosed by staging $\mathrm{CT}$. The management pathway was chosen according to TNM staging. For patients with locally advanced EGAC (pT3 or pT4), re-staging was carried out after the completion of neoadjuvant chemotherapy, in order to plan surgical management.

\section{Chemotherapy and surgical resection}

Perioperative chemotherapy consists of four cycles prior to surgery (over 8 weeks) and further four cycles post-surgery, with each cycle lasting 2 weeks. The FLOT regime consists of infusions of $5-\mathrm{FU} 2600 \mathrm{mg} / \mathrm{m}^{2}$ $(24 \mathrm{~h})$, leucovorin $200 \mathrm{mg} / \mathrm{m}^{2}(2 \mathrm{~h})$, oxaliplatin $85 \mathrm{mg} /$ $\mathrm{m}^{2}(2 \mathrm{~h})$ and docetaxel $50 \mathrm{mg} / \mathrm{m} 2(1 \mathrm{~h})$ every 2 weeks [5].

Surgery was usually carried out between 4 and 6 weeks after the completion of the neoadjuvant cycles of chemotherapy, with few selected patients undergoing surgery at a later point in time. Surgery was chosen according to tumor location and size. Routinely, esophagectomy plus proximal gastrectomy with twofield lymphadenectomy was performed for esophageal or junctional adenocarcinoma (AEG I+II), whilst patients with AEG III tumors (in some selected cases also AEG II underwent transhiatal extended gastrectomy with lower mediastinal and modified DII-lymphadenectomy. Total or subtotal gastrectomy plus modified DII-lymphadenectomy was performed for patients with gastric cancer. In extended tumors, the surgical approach was adapted as necessary. Resectability of the primary and metastases depended on the location and was determined by an interdisciplinary team. It was then carried out accordingly e.g. as liver resection, adrenalectomy or peritonectomy for peritoneal carcinomatosis. Hyperthermic intraperitoneal chemotherapy (HIPEC) was additionally performed for patients with limited peritoneal metastases using Cisplatin $\left(75 \mathrm{mg} / \mathrm{m}^{2}\right)$ and Doxorubicin $\left(15 \mathrm{mg} / \mathrm{m}^{2}\right)$. No peritoneal lavage cytology was performed for patients in this cohort. Routine postoperative standard histopathological workup and staging was performed. 


\section{Statistical analysis}

Statistical analysis was performed using IBM SPSS statistics, Version 23. Categorical variables were put in absolute and relative frequencies; differences were evaluated by Chi-Square or Fisher's exact test as appropriate. Quantitative values were expressed as medians with range and differences were measured using the Mann-Whitney-U test. Multivariate analysis was performed through forward logistic regression model, with relative risk and a 95\% confidence interval. The Kaplan-Meier method was used to evaluate survival, with a long-rank test for the comparison of subgroups. A p-value $<0.05$ was considered statistically significant.

\section{Results}

\section{Early results}

Out of 48 patients, 31 patients (65\%) were diagnosed with gastric cancer and 17 patients (35\%) with esophageal adenocarcinoma. Median follow up was 13 months (11 months for deceased patients and 17 months for all others). All patients, except for one (pT2), had pT3 or pT4 tumors at initial staging. Comorbidities, including cardiac, pulmonary, renal and hepatic disease were present in $64 \%$ of patients $(n=31)$. Other patients' characteristics are summarized in Table $1.83 \%$ of patients completed four cycles of neoadjuvant FLOT chemotherapy $(n=40)$, whereas the adherence to postoperative chemotherapy was less, with only 31 patients (65\%) completing their adjuvant treatment. Potentially resectable metastases were present in all patients either at the time of initial diagnosis or during preoperative staging. Figure 1 shows patient selection through a flowchart of diagnosis and staging (Fig. 1).

$62 \%$ of patients $(n=30)$ had peritoneal carcinomatosis, from which $84 \%$ arose from gastric cancer $(n=26)$.

Table 1 Distribution of demographics for patients with oligometastatic EGAC

\begin{tabular}{llll}
\hline & Gastric carcinoma $(\mathbf{n}=\mathbf{3 1})$ & Esophageal carcinoma $(\mathbf{n}=\mathbf{1 7})$ & Total $(\mathbf{n}=\mathbf{4 8})$ \\
\hline Sex & & & $15(31 \%)$ \\
Female & $11(35 \%)$ & $4(23 \%)$ & $33(69 \%)$ \\
Male & $20(64 \%)$ & $13(76 \%)$ & $56.8(30.2-81.2)$ \\
Age in years* & $55.1(33.6-81.1)$ & $58.3(30.2-80)$ & $29(60 \%)$ \\
ASA classification & & & $19(39 \%)$ \\
ASA 1-2 & $17(55 \%)$ & $5(29 \%)$ & $25.3(18.0-41.7)$ \\
ASA 3-4 & $14(45 \%)$ & $24.5(20.5-38.1)$ & \\
BMl in kg/m & $26.3(18.0-41.7)$ & & \\
\hline
\end{tabular}

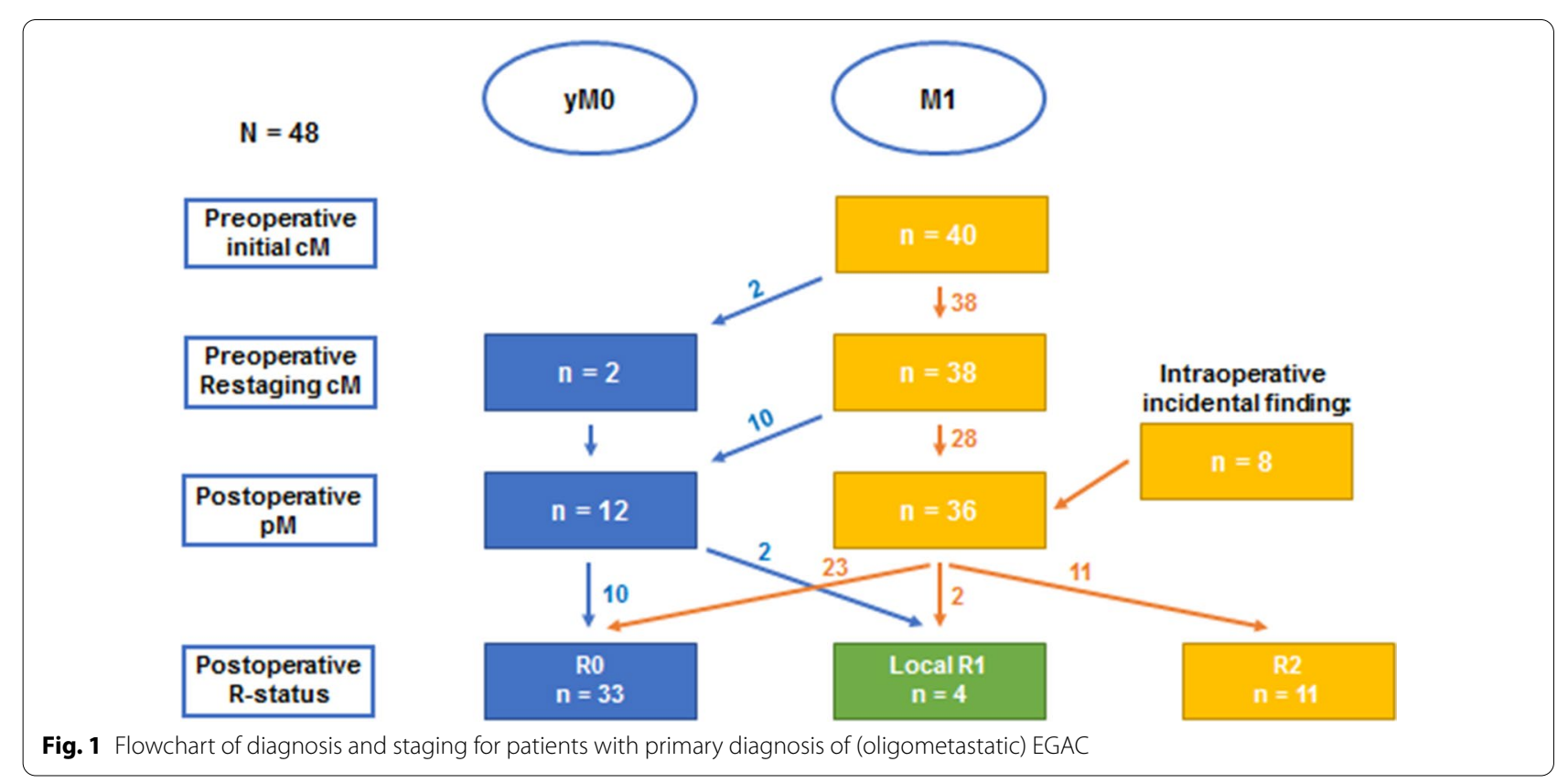


Distant lymph node metastases (lymph nodes outside of DI-II resection area) were found in 7 patients, other distant metastases sites were hepatic $(n=7)$, adrenal $(\mathrm{n}=3)$ and pulmonary $(\mathrm{n}=1)$. Complete remission of metastases after preoperative chemotherapy was achieved in 12 patients (Fig. 1). Out of these 12 patients (ypM0), 8 did not show evidence of metastatic lesions, both during the preoperative staging and intraoperatively, and 4 patients with macroscopically suspected peritoneal carcinomatosis showed no histologic evidence of tumor cells after peritonectomy. Resection of metastases was performed if distant metastases could be detected intraoperatively and surgical resection seemed feasible. Thus, in $68 \%$ of patients $(n=33)$ simultaneous resection of metastases was performed. For 11 patients (23\%) metastases were not feasible to resect, defined here as R2. HIPEC was additionally carried out in 15 patients with peritoneal metastases after complete cytoreductive surgery.

\section{Complications and length of stay}

Postoperative complications occurred in $48 \%$ of patients $(\mathrm{n}=23)[42 \%$ after gastrectomy $(\mathrm{n}=13)$ and $59 \%$ after esophagectomy $(n=10)]$. Surgical complications include anastomotic leaks $(\mathrm{n}=2)$ wound infection $(\mathrm{n}=5)$, chylothorax $(n=3)$ and haemorrhage $(n=2)$, whilst medical complications were mainly pulmonary, such as pleural effusions $(n=4)$, pneumonia $(n=8)$ and the need for reintubation $(n=2) .16$ patients $(33 \%)$ experienced complications of grade I-II and seven patients had major complications of grade III-V (15\%). Two patients died after esophagectomy: one patient due to postoperative arrosive bleeding from the splenic artery and one due to rapid progressive pleural carcinomatosis, and one patient after gastrectomy, due to an anastomotic leak followed by septic shock. Average length of hospital stay was 12 days (range 7-94), with an average length of stay on ICU/IMC of 4 days (range 2-22 days). Treatment data is summarized in Table 2.

\section{Overall survival}

Overall 5- year survival of patients with oligometastatic EGAC was $18 \%$, with a median survival of 15 months after surgery. Tumor recurrence occurred in 51\% (19 of 37 patients) without residual macroscopic tumor after surgery, in a median time interval of 6 months (1-15). Most recurrences were distant metastases (peritoneal carcinomatosis $\mathrm{n}=5$, hepatic $\mathrm{n}=6$, multiple distant $\mathrm{n}=1$ ). Post-recurrence treatment was individualized to the patient and included surgery, radiotherapy, palliative chemotherapy or best supportive care. According to the treatment used, the rate of overall survival will differ. Patients with gastric cancer and esophageal adenocarcinoma had 5-year survival rates of $25 \%$ and $10 \%$ respectively $(\mathrm{p}=0.213)$. Tumor regression grading according to Becker et al. [12], showed that with 1a regression (no residual tumor, $\mathrm{n}=6$ ), patients had a $60 \%$ survival at 5 years. Patients with regression grades of $1 \mathrm{~b}$ and 2 only had $11 \%$ and grade 3 and above only 12\% 5year survival ( $\mathrm{p}=0.012$, Table 3, Fig. 2). Median survival was 21 months and 9 months, respectively. The survival rate was shown to be $60 \%$ for patients with T0 staging, compared to $27 \%$ for $\mathrm{T} 1 / \mathrm{T} 2$ and $0 \%$ for $\mathrm{T} 3 / \mathrm{T} 4$ tumors $(\mathrm{n}=6, \mathrm{n}=15, \mathrm{n}=27$, respectively, $\mathrm{p}=0.047)$. The most significant finding was demonstrated by the difference in 5 -year survival rate between patients with non-detectable tumor postoperatively (ypM0) and patients with detectable oligometastases. Here, patients with postoperative ypM0 $(n=12)$ had a $48 \% 5$-year survival rate, with a median survival of 47 months, in contrast to only $11 \%$ at 5 years for patients with detectable tumor cells (ypM1, $\mathrm{n}=36)$, with a median of 12 months $(\mathrm{p}=0.012)$. Furthermore, the overall survival of patients with ypM0 is comparable to patients without metastatic disease at primary diagnosis (cM0), with $48 \%$ and $51 \%$ respectively ( $<<0.001$; Fig. 3). There is no significant difference in overall survival between patients with resected metastases, and those without resection ( $9 \%$ vs $17 \% \mathrm{p}=0.427$; Fig. 4). The location of metastases, resection margin or nodal status (Fig. 5) had no significant correlation for 5 -year survival $(\mathrm{p}=0.945, \mathrm{p}=0.273, \mathrm{p}=0.062)$. Postoperative T-stage showed an influence on 5 -year survival $(\mathrm{p}=0.047)$. Multivariate analysis regarding $\mathrm{T}-, \mathrm{N}-$ and $\mathrm{M}$-staging, $\mathrm{R}$-status or regression grade showed that the absence of metastases (ypM0) is an independent predictor of overall survival ( $\mathrm{p}=0.018$; RR 3.612, KI 12.4610.470). Results are summarized in Table 3.

\section{Discussion}

Multimodal treatment strategies have significantly improved the long-term results in the treatment of non-metastatic EGAC. Up to date, there is an ongoing debate about the best treatment option for EGAC with oligometastatic disease. Synchronous metastatic disease is seen in up to $14 \%$ of cases [13, 14]. Up to date, guidelines across Europe do not recommend multimodal treatment including surgery for patients with distant metastases, but rather recommend palliative chemotherapy $[6,15,16]$. The value of surgery for metastases, especially for liver metastases originating from colorectal cancer, has evolved over the last few years as it has been shown to improve long-term and disease-free survival, with 5 year survival rates of $25-40 \%$ [17, 18]. Thus, the option of surgery as a potential curative treatment is standardly offered to patients with hepatic metastatic colorectal disease. 
Table 2 Details of surgical intervention and postoperative treatment data including complications and recurrence

\begin{tabular}{|c|c|c|c|}
\hline & Gastric carcinoma $(n=31)$ & Esophageal carcinoma $(n=17)$ & Total $(n=48)$ \\
\hline \multicolumn{4}{|l|}{ Type of surgery } \\
\hline Esophagectomy & $1(3 \%)$ & $15(88 \%)$ & $16(33 \%)$ \\
\hline Gastrectomy & 30 (97\%) & $2(12 \%)$ & $32(66 \%)$ \\
\hline HIPEC & $14(45 \%)$ & $1(6 \%)$ & $15(31 \%)$ \\
\hline \multicolumn{4}{|l|}{ Additional resection } \\
\hline None & $10(32 \%)$ & $5(29 \%)$ & $15(31 \%)$ \\
\hline Peritoneum & $16(51 \%)$ & $2(12 \%)$ & $18(37 \%)$ \\
\hline Distant lymph nodes & $1(3 \%)$ & $3(18 \%)$ & $4(8 \%)$ \\
\hline Liver & $1(3 \%)$ & $3(18 \%)$ & $4(8 \%)$ \\
\hline Adrenal & $3(10 \%)$ & 0 & $3(6 \%)$ \\
\hline Multivisceral resection & 0 & $4(24 \%)$ & $4(8 \%)$ \\
\hline Perioperative in-patient stay in days & $11(8-23)$ & $14(7-94)$ & $12(7-94)$ \\
\hline Perioperative in intensive care in days & $4(2-11)$ & $5(3-22)$ & $4(2-22)$ \\
\hline \multicolumn{4}{|l|}{ Perioperative complications } \\
\hline Clavien Dindo & $13(42 \%)$ & $10(59 \%)$ & $23(48 \%)$ \\
\hline$|/| \mid$ & $9(29 \%)$ & $7(41 \%)$ & $16(33 \%)$ \\
\hline III/IV & $3(10 \%)$ & $1(6 \%)$ & $4(8 \%)$ \\
\hline V & $1(3 \%)$ & $2(12 \%)$ & $3(6 \%)$ \\
\hline \multicolumn{4}{|l|}{ Resection margin } \\
\hline Ro & $21(68 \%)$ & $12(70 \%)$ & $33(69 \%)$ \\
\hline R1 (primary tumor) & $3(9 \%)$ & $1(6 \%)$ & $4(8 \%)$ \\
\hline R2 (non-resected metastases) & $7(22 \%)$ & $4(23 \%)$ & $11(23 \%)$ \\
\hline \multicolumn{4}{|l|}{ Postoperative residual tumor } \\
\hline Local & $3(10 \%)$ & $1(6 \%)$ & $4(8 \%)$ \\
\hline Peritoneal carcinomatosis & $3(10 \%)$ & $2(12 \%)$ & $5(10 \%)$ \\
\hline Lymph nodes & $1(3 \%)$ & $2(12 \%)$ & $3(6 \%)$ \\
\hline Distant metastasis & $3(10 \%)$ & 0 & $3(6 \%)$ \\
\hline Recurrence & $12(39 \%)$ & $7(41 \%)$ & $19(40 \%)$ \\
\hline Time of recurrence after surgery in months* & $5,5(1-15)$ & $6,5(1-10)$ & $6(1-15)$ \\
\hline \multicolumn{4}{|l|}{ Type of recurrence } \\
\hline Local & $1(8 \%)$ & 0 & $1(5 \%)$ \\
\hline Local and distant & $2(17 \%)$ & $2(29 \%)$ & $4(21 \%)$ \\
\hline Peritoneal carcinomatosis & $4(33 \%)$ & $1(14 \%)$ & $5(26 \%)$ \\
\hline Hepatic metastasis & $3(25 \%)$ & $3(43 \%)$ & $6(32 \%)$ \\
\hline Other type of metastasis & $1(8 \%)$ & $1(14 \%)$ & $2(11 \%)$ \\
\hline
\end{tabular}

Furthermore, even though the addition of treatment modalities like cytoreductive surgery and HIPEC have been shown to prolong survival in selected patients with gastrointestinal and gynecological tumors there is in an ongoing debate about the best management of patients with metastatic disease [19-21]. Although some retrospective studies suggest an improved survival of patients with surgical resection of metastases for EGAC [22, 23], there is a lack of prospective, randomized evidence. There is currently an ongoing RCT comparing surgical intervention for oligometastatic disease to the effectiveness of palliative chemotherapy [10].

Comparing our survival data with the existing literature, certain consistencies can be identified. The median survival of all patients included in this study was 15 months, the data in the literature ranges from 13 to 31 months [9, 10, 13]. Most definitions of oligometastatic disease, however, do not include peritoneal carcinomatosis. A difference in 5-year survival is shown between lymphatic and hepatic metastases $(43 \%$ and $40 \%)$ compared to peritoneal carcinomatosis of $11 \%$, suggesting 
Table 3 Univariate analysis of factors influencing 5-year survival after resection of oligometastatic EGAC

\begin{tabular}{|c|c|c|c|c|}
\hline & $\mathbf{n}$ & 5-year-survival (\%) & Median survival in years & $p=$ \\
\hline Total & 48 & 18 & 1.3 & \\
\hline \multicolumn{5}{|l|}{ Sex } \\
\hline Female & 15 & 26 & 2.8 & 0.195 \\
\hline Male & 33 & 16 & 1 & \\
\hline \multicolumn{5}{|l|}{ Age } \\
\hline$<65$ & 35 & 10 & 1.2 & 0.596 \\
\hline$\geq 65$ & 13 & 26 & 1.4 & \\
\hline \multicolumn{5}{|l|}{ ASA classification } \\
\hline ASA 1-2 & 29 & 20 & 1.3 & 0.405 \\
\hline ASA 3-4 & 19 & 16 & 1 & \\
\hline \multicolumn{5}{|l|}{ Type of carcinoma } \\
\hline Esophageal carcinoma & 17 & $10 \%$ & 1 & 0.213 \\
\hline Gastric carcinoma & 31 & $24 \%$ & 1.3 & \\
\hline \multicolumn{5}{|l|}{ Preoperative T stage } \\
\hline $\mathrm{T} 2$ & 1 & 0 & 0.5 & 0.338 \\
\hline T3 & 29 & $14 \%$ & 1.2 & \\
\hline $\mathrm{T} 4$ & 5 & 0 & 3.9 & \\
\hline \multicolumn{5}{|l|}{ Type of surgery } \\
\hline Esophagectomy & 16 & 0 & 1 & 0.099 \\
\hline Gastrectomy & 32 & 30 & 1.3 & \\
\hline \multicolumn{5}{|l|}{ Resection margin } \\
\hline RO & 33 & 21 & 1.4 & 0.273 \\
\hline R1 (primary tumor) & 4 & 0 & 0.4 & \\
\hline R2 (non-resected metastases) & 11 & 17 & 1.3 & \\
\hline \multicolumn{5}{|l|}{ Tumor regression grading } \\
\hline $1 a$ & 6 & 60 & Not reached & 0.012 \\
\hline $1 b-2$ & 22 & 11 & 1.8 & \\
\hline 03-Apr & 20 & 12 & 0.9 & \\
\hline \multicolumn{5}{|l|}{ Postop. pathologic T stage } \\
\hline TO & 6 & 60 & Not reached & 0.047 \\
\hline $\mathrm{T} 1-\mathrm{T} 2$ & 15 & 27 & 1.3 & \\
\hline T3-T4 & 27 & 0 & 1 & \\
\hline \multicolumn{5}{|l|}{ Postop. pathologic N stage } \\
\hline NO & 17 & 31 & 2.9 & 0.062 \\
\hline $\mathrm{N}+$ & 31 & 11 & 1.2 & \\
\hline \multicolumn{5}{|l|}{ Type of metastasis } \\
\hline Peritoneal carcinomatosis & 30 & 11 & 1 & 0.945 \\
\hline Lymph nodes & 7 & 43 & 1.3 & \\
\hline Hepatic & 7 & 40 & 2.9 & \\
\hline Adrenal & 3 & 0 & 0.9 & \\
\hline Pulmonary & 1 & 0 & 1.7 & \\
\hline ypM0 & 12 & 48 & 3.9 & 0.427 \\
\hline ypM1 and complete resection of metastasis & 25 & 9 & 1 & \\
\hline ypM1 and no complete resection of metastasis & 11 & 17 & 1.3 & \\
\hline \multicolumn{5}{|l|}{ Status of metastasis } \\
\hline No & 12 & 48 & 3.9 & 0.012 \\
\hline Yes & 36 & 11 & 1 & \\
\hline \multicolumn{5}{|l|}{ Adjuvant chemotherapy } \\
\hline Yes & 31 & 21 & 1.7 & 0.182 \\
\hline
\end{tabular}


Table 3 (continued)

\begin{tabular}{llll}
\hline & $\mathbf{n}$ & 5-year-survival (\%) & Median survival in years \\
\hline No & 9 & 30 & 0.5 \\
\hline
\end{tabular}

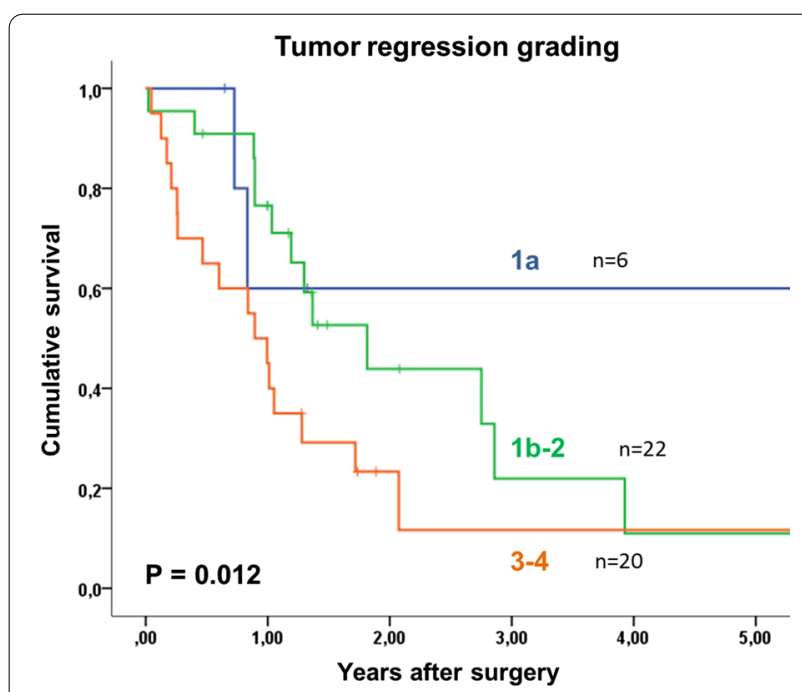

Fig. 2 Kaplan Meier 5-year survival for patients with oligometastatic EGAC depending on postoperative tumor regression grading

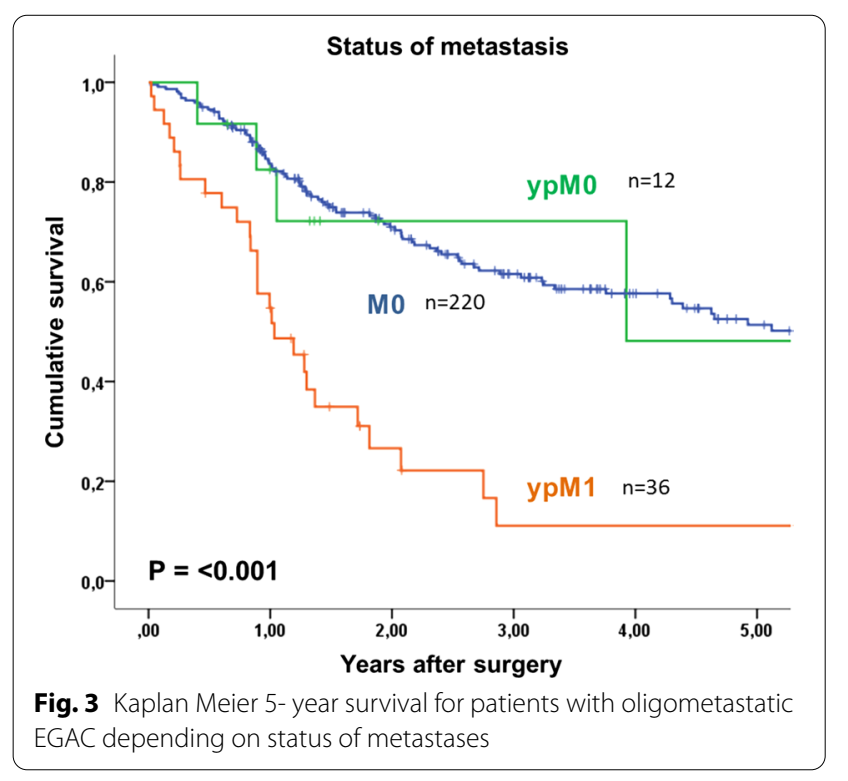

that results might differ according to which definition of oligometastases was used. Patients with peritoneal carcinomatosis are often only treated with best supportive care or palliative chemotherapy, with a median survival of 4 and 7 months, respectively [24]. Our data suggests median survival rates of 13 months for patients with

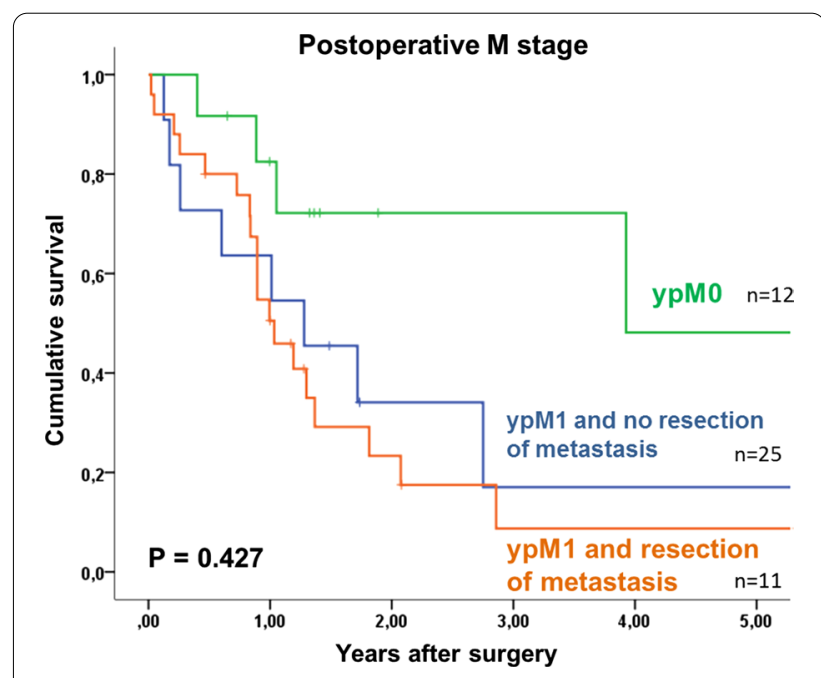

Fig. 4 Kaplan Meier 5-year survival for patients with oligometastatic EGAC depending on postoperative M-stage

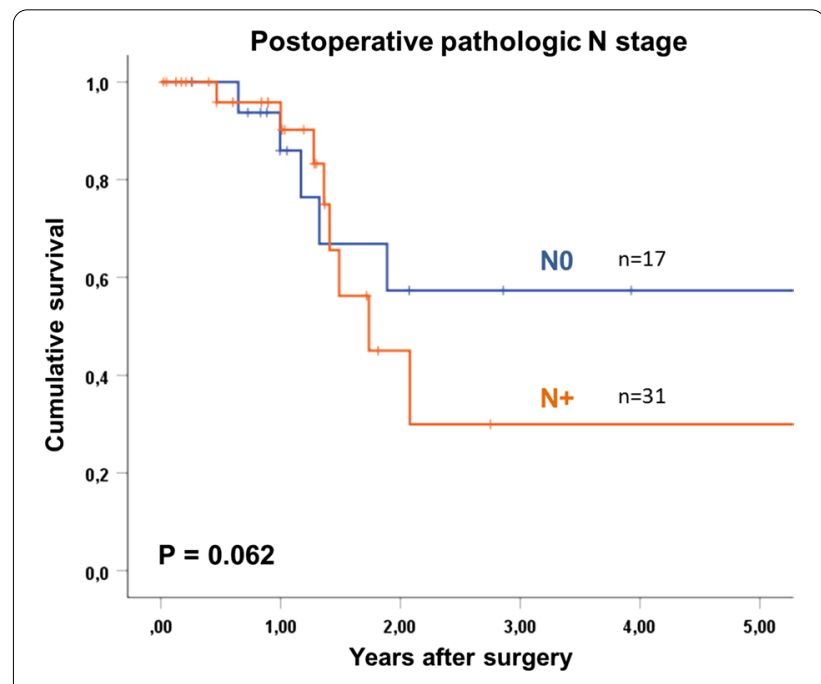

Fig. 5 Kaplan Meier 5-year survival for patients with oligometastatic EGAC depending on postoperative pathologic $\mathrm{N}$-staging

peritoneal carcinomatosis and perioperative chemotherapy followed by surgery, with 15 patients receiving additional HIPEC. The median survival correlates with data found in the literature regarding HIPEC and gastric cancers quoting median survival of between 10 and 21 months [25-27]. Although some authors suggest an improved overall survival for patients with limited 
peritoneal metastatic disease and HIPEC, it is not introduced in national and international treatment guidelines for patients with EGAC [25, 26, 28-30].

Different studies suggest a significantly improved overall survival of patients with surgical resection of the primary EGAC and metastases [8-10, 13, 14, 31], although results from RCTs are still anticipated. Patients without any detectable metastases after perioperative chemotherapy and surgical resection (ypM0) had a similar overall survival to patients without any metastatic disease at primary diagnosis ( $48 \%$ and $52 \%$ at 5 years, respectively), demonstrating the effectiveness of good response to neoadjuvant chemotherapy. Median survival for patients with ypM0 of 47 months compares to median survival quoted in the literature for patients after FLOT therapy for locally advanced tumors of 50 months [5]. The phase 2 AIO-FLOT3 trial suggests better overall survival after resection compared to chemotherapy alone, quoting almost double the median survival (31.3 months vs 15.9 months) [31]. Patients selected for surgery of metastases had to show a chance of R0 resection of the primary and metastatic lesion at restaging, assuming a good response to preoperative chemotherapy. Metastases found intraoperatively suggest either progress of disease or lack of sensitivity of staging diagnostics. To the contrary an Asian RCT compared chemotherapy alone to a multimodal therapeutic approach and randomly assigned 175 patients with advanced gastric cancer and oligometastasis to either chemotherapy or gastrectomy followed by chemotherapy [32]. The multimodal treatment option of surgery followed by chemotherapy failed to show survival benefit over chemotherapy alone. Furthermore, complications associated with chemotherapy were higher in those who underwent gastrectomy beforehand, suggesting that additional surgery leads to decreased survival rates and higher rates of chemotherapy-associated complications [32]. Although our results suggest no additional benefit from surgical resection of the metastases, the comparison to the Asian trial is difficult. All our patients received neoadjuvant FLOT chemotherapy followed by resection; a comparison to chemotherapy alone was not made.

Similar to our results, a large retrospective analysis of 5185 patients did not show a survival benefit of simultaneous resection of metastases compared to resection of the primary alone [33]. Prognostic factors were pT- staging, regression grading and type of recurrence. Although some studies suggest significant influence of age, gender, sex, tumor location and nodal stage $[2,8,13,34]$ a significance could not be reproduced for patients with oligometastatic disease from EGAC. The results found in the available literature are highly heterogeneous, thus a clear recommendation of treatment for oligometastatic disease from EGAC is difficult to construct.

Limitations of this study included foremost the sample size of 48 heterogenous patients and the retrospective, non-randomized nature of this study. The patients analyzed in this manuscript are a highly selected collective of patients with metastasized EGAC, who underwent surgical resection. The majority of patients with metastatic disease received palliative chemotherapy only, and were not included in this study. Secondly, all types of metastases were included in our study, with some patients receiving additional HIPEC. There is a lack of a clear, agreed upon definition of oligometastases, thus a comparison within the literature is difficult. The inclusion of patients with peritoneal carcinomatosis could potentially skew the results. In single cases a misdiagnosis of preoperative cM1 status in patients with postoperative ypM0 status is possible and may thus create a bias. Furthermore, a multidisciplinary tumor board only selected patients with a good response to chemotherapy to proceed to surgery, for a potential cure of malignant disease.

\section{Conclusions}

Although the current literature suggests improved overall survival for patients with perioperative FLOT and additional surgical resection of metastatic lesions, we could not establish a significant benefit for survival for patients undergoing additional resection of metastases compared to those, where only the primary tumor was resected. Oligometastatic EGAC is associated with overall poor survival rates, despite complete resection of all tumor manifestations. However, survival rates for patients with complete response after FLOT and surgical resection match survival rates of patients without any metastatic disease at primary diagnosis. The results from RCTs are needed to evaluate the significance of additional surgery for metastases, in order to define the best option for patients with oligometastatic disease in the era of multimodal treatment of EGAC.

\section{Abbreviations}

FLOT: Chemotherpapy consisting of Docetaxel, Oxaliplatin, Leucovorin and 5FU; EGAC: Esophagogastric adenocarcinoma; RCT: Randomized controlled trial; ECF: Chemotherapy consisting of Epirubicin, Cisplatin and 5FU; ECX: Chemotherapy consisting of Epirubicin, Cisplatin and Capecitabin; HPR: Histopathological regression; Gl: Gastrointestinal; CT: Computer tomography; PETCT: Positron emission tomography; AEG: Esophagogastric junction cancers; HIPEC: Hyperthermic intraperitoneal chemotherapy.

\section{Acknowledgements}

Not applicable.

\section{Authors' contributions}

Conceptualization: MR, TG, JH, RV. Methodology: RV, MR, TG, Formal analysis: RV, MR, TG. Writing —original draft preparation: MR. Writing—review and 
editing: JS, TG, JH, SFF. Supervision: TG, JH, SFF. All authors read and approved the final manuscript.

\section{Funding}

Open Access funding enabled and organized by Projekt DEAL. This research received no external funding.

\section{Availability of data and materials}

The datasets used and analyzed during the current study are available from the corresponding author on reasonable request.

\section{Ethics approval and consent to participate}

The study was approved by the Medical Ethics Committee of the University of Freiburg (File number 253/19).

\section{Consent for publication}

Not applicable.

\section{Competing interests}

The authors declare that they have no competing interests.

\section{Author details}

${ }^{1}$ Department of General - and Visceral Surgery, Medical Center, University of Freiburg, Hugstetterstrasse 55, 79106 Freiburg, Germany. ${ }^{2}$ Present Address: Department of Surgery, University Medical Center Schleswig-Holstein, Campus Luebeck, Luebeck, Germany. ${ }^{3}$ Present Address: Department of Surgery, Marien Hospital Herne, Ruhr-University Bochum, 44625 Herne, Germany.

Received: 5 October 2020 Accepted: 27 December 2020

Published online: 13 January 2021

\section{References}

1. Cunningham D, Allum WH, Stenning SP, Thompson JN, Van de Velde CJ, Nicolson M, Scarffe JH, Lofts FJ, Falk SJ, Iveson TJ, et al. Perioperative chemotherapy versus surgery alone for resectable gastroesophageal cancer. N Engl J Med. 2006;355(1):11-20.

2. Wang $K$, Ren Y, Ma Z, Li F, Cheng X, Xiao J, Zhang S, Yu Z, Yang H, Zhou $\mathrm{H}$, et al. Docetaxel, oxaliplatin, leucovorin, and 5-fluorouracil (FLOT) as preoperative and postoperative chemotherapy compared with surgery followed by chemotherapy for patients with locally advanced gastric cancer: a propensity score-based analysis. Cancer Manag Res. 2019;11:3009-20.

3. Moehler M, Baltin CT, Ebert M, Fischbach W, Gockel I, Grenacher L, Holscher AH, Lordick F, Malfertheiner P, Messmann H, et al. International comparison of the German evidence-based S3-guidelines on the diagnosis and multimodal treatment of early and locally advanced gastric cancer, including adenocarcinoma of the lower esophagus. Gastric Cancer. 2015;18(3):550-63.

4. Boige V, Pignon J, Saint-Aubert B, Lasser P, Conroy T, Bouché O, Segol $P$, Bedenne $L$, Rougier $P, Y c h o u ~ M$. Final results of a randomized trial comparing preoperative 5-fluorouracil (F)/cisplatin (P) to surgery alone in adenocarcinoma of stomach and lower esophagus (ASLE): FNLCC ACCORD07-FFCD 9703 trial. J Clin Oncol. 2007;25(18 suppl):4510-4510.

5. Al-Batran SE, Homann N, Pauligk C, Goetze TO, Meiler J, Kasper S, Kopp HG, Mayer F, Haag GM, Luley K, et al. Perioperative chemotherapy with fluorouracil plus leucovorin, oxaliplatin, and docetaxel versus fluorouracil or capecitabine plus cisplatin and epirubicin for locally advanced, resectable gastric or gastro-oesophageal junction adenocarcinoma (FLOT4): a randomised, phase 2/3 trial. Lancet. 2019;393(10184):1948-57.

6. Moehler M ea: S3-Leitlinie "Magenkarzinom"—Diagnostik und Therapie der Adenokarzinome des Magens und Ösophagogastralen Übergangs In.: Z Gastroenterol; 2001: 461-531.

7. Chiapponi C, Berlth F, Plum PS, Betzler C, Stippel DL, Popp F, Bruns CJ. Oligometastatic disease in upper gastrointestinal cancer - how to proceed? Visceral medicine. 2017;33(1):31-4.

8. Beckert S, Königsrainer A. Oligometastasierung beim Magen- und Ösophaguskarzinom. Der Chirurg. 2018;89(7):505-9.

9. Carmona-Bayonas A, Jimenez-Fonseca P, Echavarria I, Sanchez Canovas M, Aguado G, Gallego J, Custodio A, Hernandez R, Viudez A, Cano JM, et al. Surgery for metastases for esophageal-gastric cancer in the real world: data from the AGAMENON national registry. Eur J Surg Oncol. 2018;44(8):1191-8.

10. Al-Batran SE, Goetze TO, Mueller DW, Vogel A, Winkler M, Lorenzen S, Novotny A, Pauligk C, Homann N, Jungbluth T, et al. The RENAISSANCE (AIO-FLOT5) trial: effect of chemotherapy alone vs. chemotherapy followed by surgical resection on survival and quality of life in patients with limited-metastatic adenocarcinoma of the stomach or esophagogastric junction - a phase III trial of the German AIO/CAO-V/CAOGI. BMC Cancer. 2017; 17(1):893

11. Dindo D, Demartines N, Clavien PA. Classification of surgical complications: a new proposal with evaluation in a cohort of 6336 patients and results of a survey. Ann Surg. 2004;240(2):205-13.

12. Becker K, Mueller JD, Schulmacher C, Ott K, Fink U, Busch R, Bottcher K, Siewert JR, Hofler H. Histomorphology and grading of regression in gastric carcinoma treated with neoadjuvant chemotherapy. Cancer. 2003;98(7):1521-30.

13. Markar SR, Mikhail S, Malietzis G, Athanasiou T, Mariette C, Sasako M, Hanna GB. Influence of surgical resection of hepatic metastases from gastric adenocarcinoma on long-term survival: systematic review and pooled analysis. Ann Surg. 2016;263(6):1092-101.

14. Song A, Zhang X, Yu F, Li D, Shao W, Zhou Y. Surgical resection for hepatic metastasis from gastric cancer: a multi- institution study. Oncotarget. 2017:8(41):71147-53.

15. Alderson D. Scottish Intercollegiate Guidelines Network (SIGN) 87 \& the management of oesophageal and gastric cancer. Clin Oncol. 2008;20(7):530-1.

16. Allum WH, Blazeby JM, Griffin SM, Cunningham D, Jankowski JA, Wong R. Guidelines for the management of oesophageal and gastric cancer. Gut. 2011;60(11):1449-72.

17. Hurwitz H, Fehrenbacher L, Novotny W, Cartwright T, Hainsworth J, Heim W, Berlin J, Baron A, Griffing S, Holmgren E, et al. Bevacizumab plus irinotecan, fluorouracil, and leucovorin for metastatic colorectal cancer. N Engl J Med. 2004;350(23):2335-42.

18. Tomlinson JS, Jarnagin WR, DeMatteo RP, Fong Y, Kornprat P, Gonen M, Kemeny N, Brennan MF, Blumgart LH, D'Angelica M. Actual 10-year survival after resection of colorectal liver metastases defines cure. J Clin Oncol. 2007;25(29):4575-80.

19. Teo MCC, Tan GHC. Cytoreductive surgery and hyperthermic intraperitoneal chemotherapy in gastrointestinal cancers: fad or standard of care? Singapore Med J. 2018;59(3):116-20.

20. Morris EJ, Forman D, Thomas JD, Quirke P, Taylor EF, Fairley L, Cottier B, Poston G. Surgical management and outcomes of colorectal cancer liver metastases. Br J Surg. 2010;97(7):1110-8.

21. Rees M, Tekkis PP, Welsh FK, O'Rourke T, John TG. Evaluation of long-term survival after hepatic resection for metastatic colorectal cancer: a multifactorial model of 929 patients. Ann Surg. 2008;247(1):125-35.

22. Hartgrink HH, Putter H, Klein Kranenbarg E, Bonenkamp JJ, van de Velde CJ. Value of palliative resection in gastric cancer. Br J Surg. 2002;89(11):1438-43.

23. Cheon SH, Rha SY, Jeung H-C, Im C-K, Kim SH, Kim HR, Ahn JB, Roh JK, Noh SH, Chung HC. Survival benefit of combined curative resection of the stomach (D2 resection) and liver in gastric cancer patients with liver metastases. Ann Oncol. 2008;19(6):1146-53.

24. Johnston FM, Beckman M. Updates on management of gastric cancer. Curr Oncol Rep. 2019;21(8):67.

25. Rau B, Brandl A, Piso P, Pelz J, Busch P, Demtröder C, Schüle S, Schlitt H-J, Roitman M, Tepel I et al: Peritoneal metastasis in gastric cancer: results from the German database. Gastric Cancer. 2019.

26. Manzanedo I, Pereira F, Rihuete Caro C, Pérez-Viejo E, Serrano A, Gutiérrez Calvo A, Regueira FM, Casado-Adam A, Cascales-Campos PA, Arteaga X, et al. Cytoreductive surgery and hyperthermic intraperitoneal chemotherapy (HIPEC) for gastric cancer with peritoneal carcinomatosis: multicenter study of spanish group of peritoneal oncologic surgery (GECOP). Ann Surg Oncol. 2019;26(8):2615-21.

27. Rau B, Brandl A, Thuss-Patience P, Bergner F, Raue W, Arnold A, Horst D, Pratschke J, Biebl M: The efficacy of treatment options for patients with gastric cancer and peritoneal metastasis. Gastric Cancer. 2019.

28. Feingold PL, Kwong MLM, Sabesan A, Sorber R, Rudloff U. Cytoreductive surgery and hyperthermic intraperitoneal chemotherapy for gastric 
cancer and other less common disease histologies: is it time? J Gastrointestinal Oncol. 2016;7(1):87-98.

29. Koemans WJ, van der Kaaij RT, Boot H, Buffart T, Veenhof A, Hartemink KJ, Grootscholten C, Snaebjornsson P, Retel VP, van Tinteren H, et al. Cytoreductive surgery and hyperthermic intraperitoneal chemotherapy versus palliative systemic chemotherapy in stomach cancer patients with peritoneal dissemination, the study protocol of a multicentre randomised controlled trial (PERISCOPE II). BMC Cancer. 2019;19(1):420.

30. Yarema R, Mielko J, Fetsych T, Ohorchak M, Skorzewska M, RawiczPruszynski K, Mashukov A, Maksimovsky V, Jastrzebski T, Polkowski W, et al. Hyperthermic intraperitoneal chemotherapy (HIPEC) in combined treatment of locally advanced and intraperitonealy disseminated gastric cancer: a retrospective cooperative Central-Eastern European study. Cancer Med. 2019;8(6):2877-85.

31. Al-Batran SE, Homann N, Pauligk C, Illerhaus G, Martens UM, Stoehlmacher J, Schmalenberg H, Luley KB, Prasnikar N, Egger M, et al. Effect of neoadjuvant chemotherapy followed by surgical resection on survival in patients with limited metastatic gastric or gastroesophageal junction cancer: the AIO-FLOT3 trial. JAMA oncology. 2017;3(9):1237-44.
32. Fujitani K, Yang HK, Mizusawa J, Kim YW, Terashima M, Han SU, Iwasaki Y, Hyung WJ, Takagane A, Park DJ, et al. Gastrectomy plus chemotherapy versus chemotherapy alone for advanced gastric cancer with a single non-curable factor (REGATTA): a phase 3, randomised controlled trial. Lancet Oncol. 2016;17(3):309-18.

33. Chen J, Kong Y, Weng S, Dong C, Zhu L, Yang Z, Zhong J, Yuan Y. Outcomes of surgery for gastric cancer with distant metastases: a retrospective study from the SEER database. Oncotarget. 2017;8(3):4342-51.

34. Yang D, Hendifar A, Lenz C, Togawa K, Lenz F, Lurje G, Pohl A, Winder T, Ning $Y$, Groshen S, et al. Survival of metastatic gastric cancer: Significance of age, sex and race/ethnicity. J Gastrointest Oncol. 2011;2(2):77-84.

\section{Publisher's Note}

Springer Nature remains neutral with regard to jurisdictional claims in published maps and institutional affiliations.
Ready to submit your research? Choose BMC and benefit from:

- fast, convenient online submission

- thorough peer review by experienced researchers in your field

- rapid publication on acceptance

- support for research data, including large and complex data types

- gold Open Access which fosters wider collaboration and increased citations

- maximum visibility for your research: over $100 \mathrm{M}$ website views per year

At BMC, research is always in progress.

Learn more biomedcentral.com/submissions 